\title{
Aptamer-Nanoparticle Bioconjugates for Drug Delivery
}

\author{
Veli C. Özalp and Thomas Schäfer \\ University of the Basque Country \\ Spain
}

\section{Introduction}

Drug delivery systems traditionally relied on passive diffusion mechanisms for targeting and releasing of therapeutically active molecules. The major problems associated with traditional delivery are poor specificity and dose-limited toxicity. Nanoparticles have found applicability in the development of novel drug delivery systems by easily overcoming toxicity problem. However, specificity of delivery has remained as a challenge. Developments in the methods of reaching to targeted tissue have lead to new and improved drug delivery platforms. Recently, active targeting has been incorporated by cell specific ligands such as antibodies, lectins, growth factor receptors. More recently, aptamers gained popularity in construction of novel actively targeted drug delivery systems (Ozalp et al., 2011). Considerable proportions of aptamer-based delivery systems have been incorporated to a variety of nanomaterials in order to improve their specific targeting properties (Chen et al., 2011; Zhou et al., 2011).

A successful therapy starts with diagnosis and then continues with application of right dose of therapeutic molecules to the site of diseased tissues or cells. Specific detection of cancer cells is essential for early diagnosis. Cancer cell types are diverse even within the same cancer category. Fast and accurate diagnosis requires multiple specific probes which can profile more than one type of cancer cell at a given time on the same sample. In that respect, cell-based aptamer selection can supply multiple biorecognition probe molecules for any desired number of target cell type. Early diagnosis of cancer relies largely on the sensitivity of detection methods. Nanoparticle-bioconjugates has been designed to develop high sensitivity sensors. In this chapter, we will summarize the recent developments in selecting cell specific aptamer selection and development of aptamer-targeted nanoparticles for medical applications.

\section{Selection of cell specific aptamers}

Aptamers are increasingly recognized as the future affinity molecules that can readily incorporated in nanodevices for medical applications. The recent progress in cell-specific selection methodology reconfirms this premise by supplying highly specific and high affinity aptamers for any type of diseased cells. Aptamers have generally been shown to have affinities and specificity that are comparable to antibodies. They have the advantage of 
high stability at a variety of extreme physical conditions such as high temperature, high salt and ionic conditions with reversible denaturation properties (Deng et al., 2001; Liss et al., 2002). Cell-specific apramers have been obtained by following two types of Selex procedure; by using the traditional approach i) against purified protein targets or by new approaches ii) against whole cells. Using purified proteins as targets has the advantage of technical control over assessments of enrichment during Selex procedure. However, the second approach has a clear advantage when the marker target is unknown.

\subsection{Aptamers selected for cell-specific proteins}

Aptamers are selected through a combinatorial procedure to identify short nucleic acid sequences that recognize specific targets. The procedure is based on a repeated cycle of affinity and separation. First target molecules are brought together with a library of nucleic acids. The usual number of members in such libraries is 1014-1018 random sequences. The library members will bind to target molecules if there is any recognition. The next step is the separation of bound and unbound library members through various chromatography techniques. It is commonly required to a cycle of 8 to 20 to enrich enough aptamer sequences which can be identified through sequencing since unspecific or common binder sequences will be favoured under the binding conditions. Detailed procedures on SELEX methods can be found elsewhere (Mayer, 2009). The simplest and direct way to obtain cell-specific aptamers is to isolate a marker protein that exists on the surface of target cell type and to use that protein as a target molecule in SELEX procedure. Many cell-specific aptamers have been selected using this strategy (Janas, 2011). The critical parameters for a successful selection are to identify cell-specific markers and to obtain the marker as pure starting material. Furthermore, the target that will be used in selection should be processed in such way that cell surface exposed regions of the molecule can be used during selection procedure. Several aptamers against cancer-related cells have been selected by using prufied proteins, including platelete-drived growth factor (PDGF) (Green et al., 1996), vascular endothelial growth factor (VEGF) (Ruckman et al., 1998), epidermal growth factor receptor 3 (HER3) (Chen et al., 2003), transcription factor NFkB (Cassiday et al., 2001), tenascin-C (Hicke et al., 2001), prostate-specific membrane antigen (PSMA) (Lupold et al., 2002), and ErbB in breast cancer (Kim et al., 2011).

The aptamer against ErbB is a typical selex procedure for selecting cell specific aptamers by using purified surface proteins. Epidermal growth factor receptor family (ErbB family) of receptor tyrosine kinases plays major roles in formation and progression of human cancers. Under normal physiological, ErbB receptors play important roles in some basic cellular processes such as proliferation, differentiation, motility and apoptosis. Upon ligand binding, ErbB receptors form homo- and heterodimers leading to the activation of their tyrosine kinase domain and subsequent autocatalytic phosphorylation of specific tyrosine residues in the cytoplasmic region. Amplification and overexpression of ErbB tyrosine kinases is associated with many types of solid tumors including breast, ovarian, head and neck, gastric, bladder, colorectal, salivary, renal, prostate and lung cancers (Salomon et al., 1995). ErbB receptors consist of an extracellular region, a single transmembrane region and a cytoplasmic tyrosine kinase domain (Cho et al., 2002). Thus, ErbB has been a target in cancer treatment. 2'-fluorine-modified RNA aptamers for the extracellular region of the receptor has been recently selected for their recognition of breast cancer cells (Kim and Jeong, 2011). 


\subsection{Aptamers selected for whole cells (cell-Selex)}

Cell specific aptamers can also be selected by using whole cells as target. Instead of selecting for a purified and defined target, aptamers can be selected by subtracting the background binding sequences after a selection cycle against the target. Whole-cell approach has been increasingly adapted more commonly for selecting new aptamers. Selection using live cell target means that the cell surface proteins will be in their native conformations by the right exposure as it would be in a real application. A panel of aptamers were selected for leukemia, myeloid leukemia, liver cancer, and lung cancer by using cell-Selex procedures. The aptamers selected by cell-selex resulted in high affinity specific aptamers, but more selection rounds compared to traditional selex were required (Fang et al., 2010). Figure 1 is a schematic representation of the cell-Selex approach. Complex targets such as tumor cells have been demonstrated to be compatible with the cell-Selex approach. The cell-selex procedure is easy to implement and faster than traditional Selex based methodologies. Most cell targets like cancer cells usually lack a clear marker protein which is highly specific for the type of application. Another important advantage of cell-selex is that the target

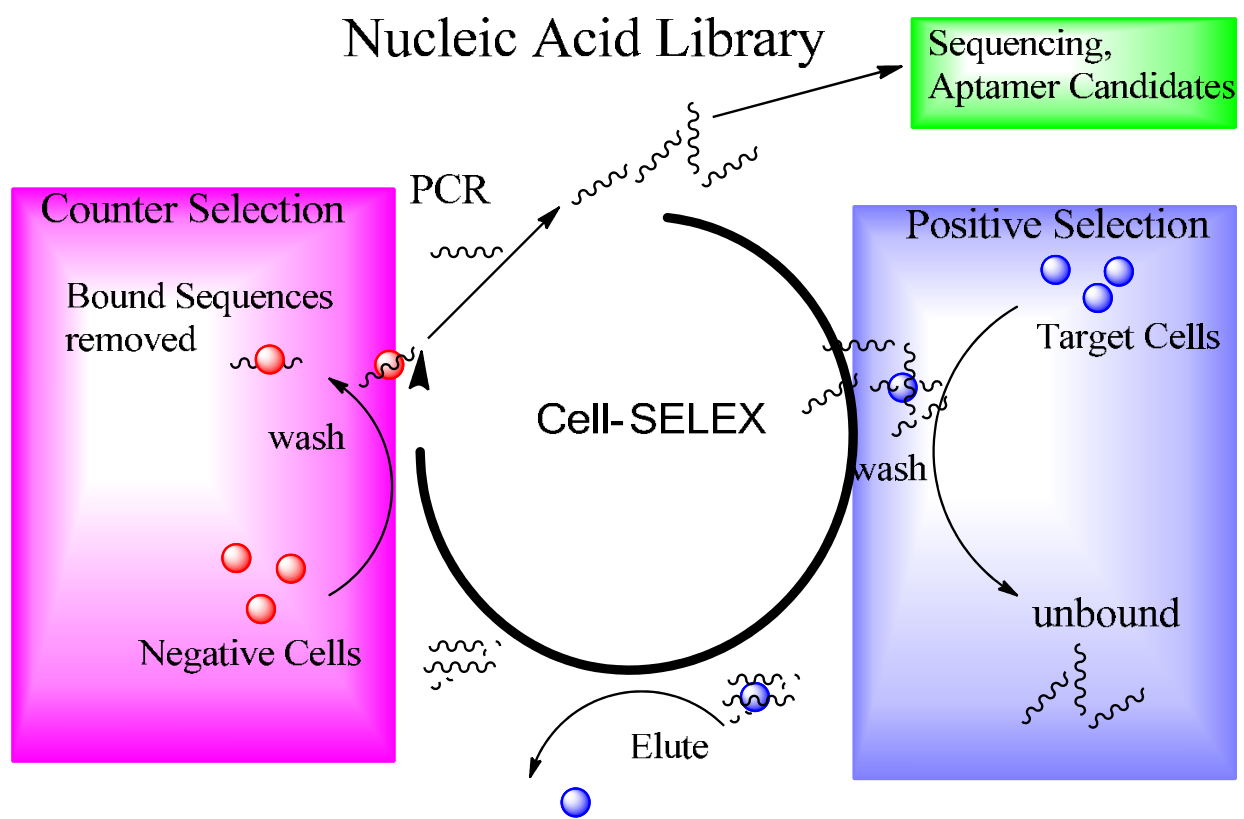

Fig. 1. Steps in a typical cell-Selex procedure. A single-stanraded DNA library was first incubated with target cells. Nano-binding sequences were washed away and the sequences bound on target cells were eluted and isolated. The recovered sequences were incubated with control cells (negative cells) to eliminate the sequences which bind to common epitopes present on both target and control cell surfaces. This step ensures the enrichment of target cell specific aptamers. The sequences specifically binding to target cells were then amplified to obtain the pool for the next round of selex. The enrichment of target cell binding sequences were evaluated using a binding assay and the sequences from last round were cloned and sequenced. 
molecules are at their optimum exposed form in vivo. A traditional selex procedure using purified marker protein can select aptamers recognizing any subregion of the protein, which can be cytoplasmic site, transmembrane regions or the regions of target proteins can be hidden when they are sitting in membrane. Therefore, cell-Selex allows a comparative strategy to identify differences at molecular levels. In this section, cell-Selex will be explained by using specific examples. However, recent reviews on cell-selex can be referred for a more detailed information (Guo et al., 2008; Fang and Tan, 2010).

\subsubsection{Aptamers targeting tumor cells}

Cancer cell types have been commonly a target for cell-Selex procedures in multiple example. An aptamer against RET receptors was selected by using cell line engineered for expressing RET tyrosine kinase receptors and background subtraction against nonexpressing cell line (Cerchia et al., 2005). Another advantage is that cell-selex can be carried out without knowing identity of surface proteins in a target cell. Moreover, it is possible to select a panel of aptamers recognizing surface proteins which does not exist in counter selection target. Cultured T cell acute lymphoblastic leucemia (CCRF-CEM) cells was used as target and human Burkitt's lymphoma B-cells for counter-selex (Shangguan et al., 2006). Flow cytometry has been used to monitor the enrichment of aptamers after each cycle and several high affinity aptamers (Kd in nanomolar ranges) have been obtained with specific recognition properties for CCRF-CEM cells in a mixture of cells. The same procedure was also adapted to adherent liver tumor cells by first detaching the cells with a non-enzymatic solution (Shangguan et al., 2008). Six aptamers for Toledo and CCRF-CEM cell lines were tested for their ability to differentiate between real samples from leucemia patients (Shangguan et al., 2007). The results showed the ability of these aptamers to specifically detect molecular differences between patients.

The identity of target on the surface of cell to which an aptamer are selected using cell-selex procedures can be determined by using post-Selex procedures. TD05 is an aptamer selected against Ramos cells by using cell-Selex methodology. The aptamer was determined to bind to Ramos cell through immunoglobulin heavy mu chain which is the heavy portion of the IgM protein. B-cell receptor complex are expressed in Ramos cells and IgM is the major component of this complex. The identification of identity of aptamer target was achieved by chemically modifying the aptamers with a photoactive uracil derivative for covalent binding of aptamer with their targets. Once aptamers are bound to targets covalently, they are isolated through magnetic extraction and the target protein was determined through mass spectroscopy techniques (Mallikaratchy et al., 2007).

\subsubsection{Aptamers targeting stem cells}

Aptamers can be used for recognition of any given cell population. The aptamer-based capture of circulating cells has been proposed for applications in regenerative medicine and tissue engineering. Mesechymal stem cells from whole bone marrow were used to generate aptamers for isolation purposes by local injection methods (Guo et al., 2006; Schaefer et al., 2007). The aptamers recognizing osteoblasts were used to enrich them quickly and efficiently on titanium surfaces (Guo et al., 2007). Stents coated with capturing agents for endothelial proginator cells (EPC) from circulating blood stream have been proposed to achieve fast enthelialization of the implanted stents and hence acceleration of the healing 
process of vascular tissue (Aoki et al., 2005; Szmitko et al., 2006). The capturing techniques was demonstrated with antibodies, peptides and aptamers (Wendel et al., 2010). In one example, aptamers for high affinity for circulating porcine EPC was selected for EPC fishing (Hoffmann et al., 2008). The application of EPC capture stents is a promising therapeutic approach to rapidly create an in vivo endothelialization of artificial surfaces. However, antibody based application has the problems due to the heterogeneity of EPC populations and the poor definition of EPC surface molecules. Therefore, the success of this approach depends on a better characterization and understanding of EPC biology and aptamers can offer the needed biorecognition molecules for the desired cell population for using in fishing approach as a successful therapy. Aptamer-based biological coatings which mimic the self healing potential of the patients' stem cell pool for vascular wall regeneration offer excitating new therapy strategies (Wendel, Avci-Adali et al., 2010). Aptamers recognizing EPC cells have also been demonstrated as one of the cell sources useful in cardiac stem cell therapy because they can contribute to neoangiogenesis and regenerate infarcted myocardium. This new therapeutic method based on aptamers was demonstrated that the transplantation of aptamer-isolated EPCs after myocardial infarction improves angiogenesis (Sobolewska et al., 2010).

\subsubsection{Aptamers targeting microbial cells}

Another group of cell specific aptamers has been selected for microbial cells. Aptamer-based detection of pathogens is an effective diagnostic tool in food industry and medicine. Aptamers targeting viruses, protozoa, or bacteria have been selected for biosensor development (Karkkainen et al., 2011). A subtype of human influenza virus has been detected by aptamers demonstrating the feasibility of using aptamers in detecting pathogenic viruses in contaminated environmental and food matrixes (Gopinath et al., 2006). African trypanosomes are a specific class of protozoan organisms responsible for the parasitic disease sleeping sickness. Aptamers specific for the African trypanosomes were reported for a surface protein located within the flagellar pocket of the parasite (Hoffmann, Paul et al., 2008) and for a surface glycoprotein of the Trypnosoma brucei subsp. Brucei (Lorger et al., 2003). Aptamers can target against some of the surface proteins of microorganism, and the growth of the bacteria can be inhibited. The only example of therapeutic aptamer with antimicrobial properties has been demonstrated with virulent Mycobacterium tuberculosis (Chen et al., 2007).

\section{Drug delivering nanoparticles}

Nanoparticles have many potential applications in medicine ranging from bioimaging to drug delivery. They have been synthesized from a variety of materials that could be degradable or stable, depending on the type of application. Although developing new types of materials is an exciting research area for future applications, pharmaceutical applications mostly rely on materials with history in human use to reduce the risks involved (Grama et al., 2011). Exposing malignant tumour cells that migrate to adjacent tissues or circulate in bloodstream is critical for early detection and effective therapy. Passive delivery refers to nanoparticles loaded with drugs are administered into body without any specific targeting. The improvement over conventional methods has been obtained by adjusting the release properties of the nanoparticles by selecting special materials during the synthesis of 
particles. On the other hand, increasing surface area to volume ratio for a delivery vehicle has huge benefits in improving solubility of biologically available drugs. Simple entrapment of bioactives inside nanoparticles has been shown to result in significantly higher bioavailability compared to their conventional administration methods (Mittal et al., 2007). Designed formulations for adjusting release rate are pursued with success in multiple examples (Cozar-Bernal et al., 2011; Tsai et al., 2011). For example, PLGA nanoparticles are biocompatible, synthesized at different grades, and safe (used for long time with humans). The release, degradation and elimination rates of PLGA nanopartiles can be tailored to desired parameters. On the other hand, nanoparticles can be functionalized for targetd delivery. Active delivery refers to incorporating a specific targeting mechanism in drugloaded nanoparticle delivery vehicle.

Aptamers have been considered as potentially interesting targeting molecules for nanoparticles. The main reason is that conjugation of aptamers to other molecules or nanoparticles is a straight-forward procedure and the attachment does not change the affinity or specificity properties of aptamers. Early diagnosis can be achieved by systems of aptamer-nanoparticle conjugates because high affinity aptamers can be obtained for tumour cells. There have been many approaches in for detection of tumor cells that is based on mechanical forces, immunohistochemistry, magnetic cell sorting, and flow cytometry. The detection based on affinity interactions is expected to yield higher efficiency and sensitivity. Antibody based affinity sensors are often found to be high levels of cross-reactivity. There are also technical challenges in crosslinking antibodies on the surface of nanodevices (Wan et al., 2010). Thus, there is an increasing recognition for aptamers as promising utility in cancer diagnosis.

Three critical steps should be considered in designing an efficient aptamer-targeted nanoparticle drug therapy; targeting, internalization and degredation of the targeted cells by release of loaded drugs (Fig. 2).

\section{Aptamer-based targeting of nanoparticles}

Aptamers are biorecognition molecules with multiple properties that make them attractive targeting elements. Aptamers can bind to their targets with high affinity and specificity, comparable to antibodies. The in vitro selection methodology is the major advantage ensuring availability for any desired application. Moreover, nucleic acids have unique properties that are frequently exploited in construction of nanomachines. A combination of all of the above-mentioned properties makes aptamers a desirable targeting agent for novel nanoparticle-based drug delivery systems. Recent developments in cell based Selex technology have raised expectations for medical applications required targeting of whole living cells. Two major medical applications of aptamer-based targeting of nanoparticles are bioimaging and drug delivery.

\subsection{Bioimaging applications}

In vivo imaging is a valuable tool in clinical diagnostics and critical to develop ultrasensitive methods (Soontornworajit et al., 2011). Many techniques of imaging from whole organism (e.g. NMR) to specific molecular imaging (e.g. Fluorescence) are available and they are envisioned to be on the focus for developing cancer diagnosis, drug delivery, guided stem 

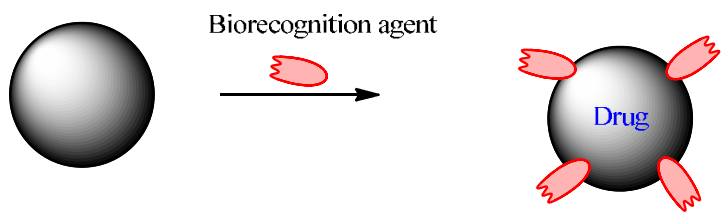

Nanoparticle

Drug loaded Nanoparticle Bioconjugate

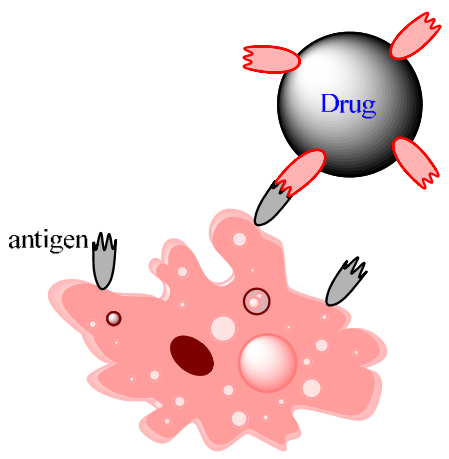

Cells with antigen

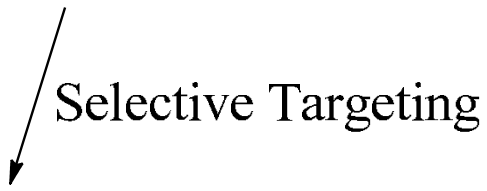

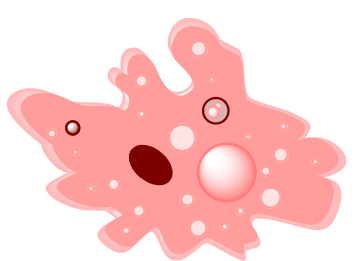

Normal Cells

\section{Internalization}

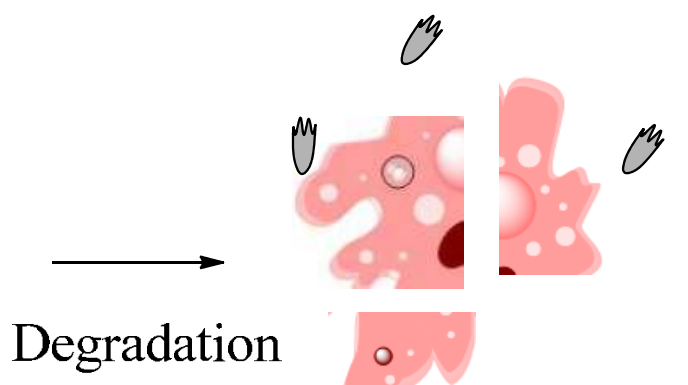

Fig. 2. A scheme of targeted Nanoparticle drug delivery. Drugs are loaded inside the nanoparticles that are conjugated to antigen-binding recognition element which bind specifically to antigen expressing cells. The nanoparticles are rapidly internalized once bound on the surface of diseased cells. The drugs encapsulated in the nanoparticles are released inside the cells and destroys the integrity of cells. 
cell therapies, imaging of gene expression to monitor disease development, gene therapy, image guided surgery (Hahn et al., 2011). Nanoparticles for bioimaging should fullfill several requirements; being dispersable and stable in vivo, low non-specific binding, and high selectivity for their targets. There are four types of nanoparticles that are commonly used in conjugation with aptamers for biological imaging applications; 1) gold nanoparticles, 2) quantum dots, 3) silica nanoparticles and 4) magnetic nanoparticles.

A nonoparticle imaging and drug delivery system has been developed by conjugating A10 aptamers to quantum dots (Bagalkot et al., 2007). Fig. 3 shows a schematic representation of aptamer-quantum dot bioconjugate for drug delivery and imaging of delivered drugs as reported. The chemotherapeutic drug doxorubicin is an nucleic acid intercalating molecules. A bi-FRET system was prepared by attaching PSMA aptamers on the surface of quantum dot nanoparticles and doxorubicin was immobilized on the aptamer molecules by intercalation. Doxorubucin is a fluorescent molecule, but quenched by gold and nucleic acids. Therefore, the system targets the doxorubicin in non-fluorescent form to the surface of prostate cell. When the drug carrier system is internalized by the cells, doxorubicin is free from aptamer and quantum dots and become fluorescent, signalling the delivery of drug into cancer cells. Another example of quantum dot-aptamer conjugates in bioimaging was to identify and isolate subpopulations of tumor cells with high specificity. In another example, quantum dots were conjugated to liver hepatoma cell line aptamers through a sterptavidinbiotin binding. The quantum-dor-aptamer complexes were shown to specifically recognize MEAR cells specifically comapered to HeLa cells and BNL cells (Zhang et al., 2010).

Aptamer conjugated magnetic nanoparticles are proposed for in vivo isolation of specific cells and also for magnetic resonance imaging (MRI) techniques. Aptamer-magnetic nanoparticles were used to isolate mesenchymal stem cells and endothelian progenitor cells for isolating "ready to transplant" cells as promising methods (Schaefer, Wiskirchen et al., 2007; Sobolewska, Avci-Adali et al., 2010). Prostate cancer specific A10 aptamers conjugated to magnetic nanoparticles were used as magnetic resonance contrast agents for lower toxicity and stronger binding properties (Wang et al., 2008).

Silica nanoparticles can be readily loaded with fluorescent molecules and highly fluorescent, stable nanoparticles can be obtained. They are stable, hydrophilic, biocompatible, chemically inert. Another advantage is that organic dyes can be encapsulated in the silica with advantages of less photobleaching. Furthermore, aptamers can be easily attached to the surface of silica. Up to 100 fold increase in sensitivity has been obtained in flow cytometry applications with dye-doped silica nanopartiles (Estevez et al., 2009). In an effort to develop sensitive monitoring of multiple cancer cell lines, three different aptamers were conjugated to fluorescent doped silica nanoparticles (Chen et al., 2009). Human acute lymphoblastic leukemia cells specific aptamer, Ramos cells specific aptamer, and Toledo cells specific aptamer were used in developing multiple assays. Nanomaterials are often used for multivalent ligand binding purposes to increase the signal and sometimes enhance the binding affinity. For example, gold-silver nanorods were used as a platform for multiple aptamer immobilization. Up to 80 aptamers could be attached to rods for obtaining 26-fold higher affinity and 300-fold higher fluorescence (Huang et al., 2008). 

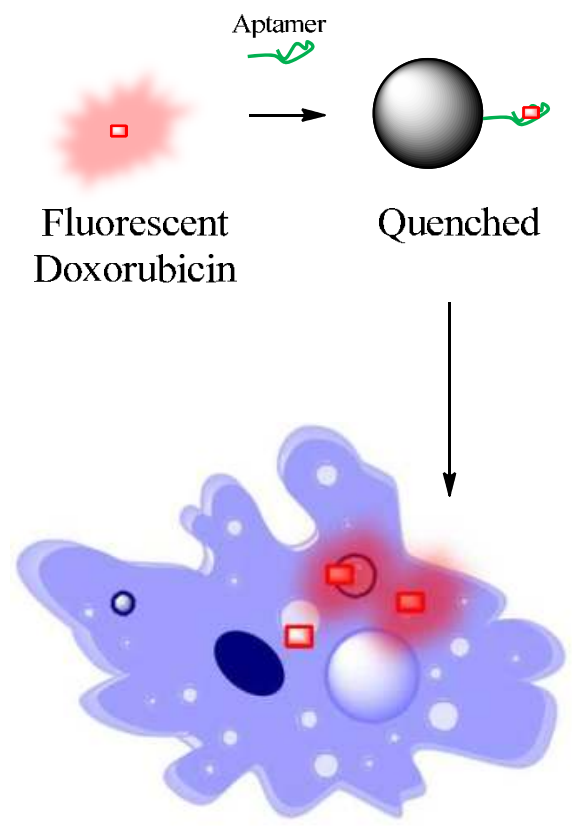

Fig. 3. Represantation of nanoparticle-aptamer based bi-FRET system for drug delivery and bioimaging. Doxorubicin is a fluophore and intercalates into nucleic acids. The fluorescence of doxorubicin is quenched by both gold and the aptamers. The quantum dot-aptamerdoxorubicin complex is targeted to tumor cells and internalized, and doxorubicin is released inside the cell, removing the quenching. The system targets the drug into diseased cells and the release of the drug can be monitored once it is delivered into desired site.

\subsection{Aptamer-targeted drug delivery in nanoparticles}

Aptamer-targeted delivery of drugs by using nanoparticles has similar advantages to bioimaging applications. The nanoparticles are specifically targeted to cell-types that are required for therapeutic molecules to act on. The drug delivery through nanoparticle encapsulation provides a vehicle for controlling the precise level and location of drugs in the body, reducing unwanted toxicity to healthy cells, lowering the doses needed. For example, drug encapsulated nanoparticles with a controlled release system can be developed and targeting to diseased cells can maximize the therapeutic efficacy and reduce undesired side effects (Langer, 2001).

Proof-of-concept nanoparticle-based vehicles have been developed for targeted drug delivery to prostate cancer cell surfaces with high specificity and efficiency. Once bound to tumor antigens, nanoparticles will be internalized through endocytosis. The toxic cargo of the nanoparticles will be released inside the tumour cells. Targeted delivery achieves a safe vehicle to destroy selectively the cancer cells. During the research of similar proof-ofconcept research, teh nanoparticles commonly loaded with fleorescent molecules to study the pathways, the success of targeting and release rate of cargo. 


\subsubsection{Prostate cancer as model system}

Aptamers potentially can direct nanoparticles to cancer cell antigens present on the surface of tumour cells. Therapeutic nanoparticles are specifically designed to encapsulate drugs and release the drugs in preregulated and predetermined way. Prostate cancer has been the first model disease for aptamer mediated nanoparticle targeting. Prostate specific membrane antigen protein (PMSA) is a well-known marker antigen which is over expressed on tumorigenic prostatic epithelial cells. Two RNA aptamer binding to extracellular portions of PSMA has been selected and shown to adhere selectively to PMSA positive cells (Lupold, Hicke et al., 2002). Later, an in vitro analysis device was developed in order to study the specific targeting properties of PMSA aptamer-nanoparticle conjugates (Farokhzad et al., 2005). The device was a model of prostate cancer targeting using a microfluidic cell under physiological fluid conditions similar to microvasculature. In this experiments, the microchannels were seeded with protate cancer epithelial cells expressing PMSA or nonexpressing cells lines. Pegylated poly(lactic acid) (PLA) particles conjugated to A10 PMSA aptamer were tested for various experimental parameters mimicking the intraveneous administration of nanoparticles. The results confirmed that the particles were rapidly internalized into PMSA positive cells. The optimized aptamer-nanoparticle vehicle loaded with the chemotherapeutic drug docetaxel was later shown to reduce tumors upon injection into mice (Farokhzad et al., 2006; Cheng et al., 2007). This example was the first targeted delivery using nanoparticle-aptamer bioconjugates. The drug delivery was achieved to be highly specific for PMSA positive cells under in vivo contions. The same system of nanoparticle-aptamer bioconjugate was shown to deliver cisplatin drug to prostate cancer cells by improving simultaneously both tolerance and efficacy in mice (Kolishetti et al., 2010).

Nanomaterials for drug delivery are required to be stable and biocompatible. Current technology can supply materials that are capable of partially fulfilling these properties. Thus, combinations of surface coatings with complementary properties are proposed for developing better functioning delivery systems. In one example, gold nanorods were encapsulated within thin and uniform layer of silica shell for enhanced stability and and a layer of PEG was used for biocompatibility. The composite nanoparticles were functionalized with PSMA aptamers and tested for their ability to target the nanopartciles to prostate cancer cells (Hu et al., 2011).

\subsubsection{Other examples}

Vasculature targeted delivery is an attractive strategy due to the phenotypic changes on the endothelial cell surface associated with pathological conditions such as inflammation and angiogenesis. E-selectin is expressed in inflammed vaculator in advanced tumors and it can be used as marker for pathological vasculator. A high affinity thio-backbone modified aptamers against E-selectin were recently selected by using recombinant-expressed protein (Mann et al., 2010). E-selection aptamers were incorporated in liposomes, the targeting efficiency and pharmokinetic properties of delivery were investigated (Mann et al., 2011). CCRF-CEM recognizing aptamers (sgc8c) were conjugated to doxorubucin-doped silica nanoparticles and delivered leukemia cells with high specificity and efficiency (He et al., 2011). 


\subsubsection{Aptamer-based gating systems}

The efficacy of drug therapy is determined by two parameters; efficient targeting of drug to the diseased site and the controlled release of the drug. The potential of aptamer-based targeting have been demonstrated in multiple examples as presented in above sections in order to improve specific delivery properties of drug carrying nanoparticles. The bioactive molecules in the nanoparticles were released with traditional mechanism such as internalization, endocytosis and degradation of nanomaterial once the nanoparticles attach to the surface of diseased cell surface. However, aptamers can be also exploited in controlling the release of drugs from nanoparticles. Two recent reports indicate to future potential of aptamers as targeting and gating agents in nanoparticle-based drug delivery. A snap-top type molecular gate using aptamer-gold nanoparticle complex to control the release of cargo of silica nanoparticles was shown to respond to aptamer target for stimuliresponsive release (Zhu et al., 2011). In another report, switchable control of the gating in nanocarriers through aptamers was shown to control the release rate of active molecules in response to taptamer target stimuli (Ozalp et al., 2011).

\section{Conclusion}

Nanoparticle-aptamer bioconjugates provide exciting prospects in medical nanotechnology for future disease treatments. The advancements in nanomaterial field together with cellSelex procedures offer the controlled release polymer systems conjugated to aptamers tweaked to the any target diseased cell. Therefore, it is possible to produce a diverse range of specific and selective nanoparticle-aptamer bioconjugates. Drug delivery vehicles can improve the therapy of a myriad of important human diseases by using aptamernanoparticle bioconjugates. Aptamer-based targeting has already achieved progress in demonstrating the usability nanoparticle-aptamer bioconjugate systems to improve nanomaterial drug delivery vehicles in model animals. Next critical step for realization of potentials of bioconjugated nanoparticles will be clinical realization studies in near future. It is worth to indicate that with aptamers being in principle available for any kind of target (e.g., small metabolites, proteins, lipids, ions), it can be anticipated a straightforward transfer of proof-of-concept results to other applications when developing efficient drugdelivery systems. Finally, aptamer-based molecular gating of nanoparticle cargo can bring new approaches in drug delivery field by combining targeting and controlled release in the same mechanism.

\section{Acknowledgment}

A starting-grant from the European Research Council (No. 209842; "MATRIX") is gratefully acknowledged.

\section{References}

Aoki, J., P. W. Serruys, H. van Beusekom, A. T. Ong, E. P. McFadden, G. Sianos, W. J. van der Giessen, E. Regar, P. J. de Feyter, H. R. Davis, S. Rowland and M. J. Kutryk (2005). "Endothelial progenitor cell capture by stents coated with antibody against 
CD34: the HEALING-FIM (Healthy Endothelial Accelerated Lining Inhibits Neointimal Growth-First In Man) Registry. J Am Coll Cardiol 45(10): 1574-9.

Bagalkot, V., L. Zhang, E. Levy-Nissenbaum, S. Jon, P. W. Kantoff, R. Langer and O. C. Farokhzad (2007). "Quantum dot - Aptamer conjugates for synchronous cancer imaging, therapy, and sensing of drug delivery based on Bi-fluorescence resonance energy transfer. Nano Letters 7(10): 3065-3070.

Cassiday, L. A. and L. J. Maher, 3rd (2001). "In vivo recognition of an RNA aptamer by its transcription factor target. Biochemistry 40(8): 2433-8.

Cerchia, L., F. Duconge, C. Pestourie, J. Boulay, Y. Aissouni, K. Gombert, B. Tavitian, V. de Franciscis and D. Libri (2005). "Neutralizing aptamers from whole-cell SELEX inhibit the RET receptor tyrosine kinase. Plos Biology 3(4): 697-704.

Cozar-Bernal, M. J., M. A. Holgado, J. L. Arias, I. Munoz-Rubio, L. Martin-Banderas, J. Alvarez-Fuentes and M. Fernandez-Arevalo (2011). "Insulin-loaded PLGA microparticles: flow focusing versus double emulsion/solvent evaporation. Journal of Microencapsulation 28(5): 430-441.

Chen, C. H. B., G. A. Chernis, V. Q. Hoang and R. Landgraf (2003). "Inhibition of heregulin signaling by an aptamer that preferentially binds to the oligomeric form of human epidermal growth factor receptor-3. Proceedings of the National Academy of Sciences of the United States of America 100(16): 9226-9231.

Chen, F., J. Zhou, F. Luo, A. B. Mohammed and X. L. Zhang (2007). "Aptamer from wholebacterium SELEX as new therapeutic reagent against virulent Mycobacterium tuberculosis. Biochem Biophys Res Commun 357(3): 743-8.

Chen, T., M. I. Shukoor, Y. Chen, Q. A. Yuan, Z. Zhu, Z. L. Zhao, B. Gulbakan and W. H. Tan (2011). "Aptamer-conjugated nanomaterials for bioanalysis and biotechnology applications. Nanoscale 3(2): 546-556.

Chen, X., M. C. Estevez, Z. Zhu, Y.-F. Huang, Y. Chen, L. Wang and W. Tan (2009). "Using Aptamer-Conjugated Fluorescence Resonance Energy Transfer Nanoparticles for Multiplexed Cancer Cell Monitoring. Analytical Chemistry 81(16): 7009-7014.

Cheng, J., B. A. Teply, I. Sherifi, J. Sung, G. Luther, F. X. Gu, E. Levy-Nissenbaum, A. F. Radovic-Moreno, R. Langer and O. C. Farokhzad (2007). "Formulation of functionalized PLGA-PEG nanoparticles for in vivo targeted drug delivery. Biomaterials 28(5): 869-876.

Cho, H. S. and D. J. Leahy (2002). "Structure of the extracellular region of HER3 reveals an interdomain tether. Science 297(5585): 1330-1333.

Deng, Q., I. German, D. Buchanan and R. T. Kennedy (2001). "Retention and separation of adenosine and analogues by affinity chromatography with an aptamer stationary phase. Analytical Chemistry 73(22): 5415-5421.

Estevez, M. C., M. B. O'Donoghue, X. Chen and W. Tan (2009). "Highly Fluorescent DyeDoped Silica Nanoparticles Increase Flow Cytometry Sensitivity for Cancer Cell Monitoring. Nano Research 2(6): 448-461.

Fang, X. H. and W. H. Tan (2010). "Aptamers Generated from Cell-SELEX for Molecular Medicine: A Chemical Biology Approach. Accounts of Chemical Research 43(1): 4857.

Farokhzad, O. C., J. J. Cheng, B. A. Teply, I. Sherifi, S. Jon, P. W. Kantoff, J. P. Richie and R. Langer (2006). "Targeted nanoparticle-aptamer bioconjugates for cancer 
chemotherapy in vivo. Proceedings of the National Academy of Sciences of the United States of America 103(16): 6315-6320.

Farokhzad, O. C., A. Khademhosseini, S. Y. Yon, A. Hermann, J. J. Cheng, C. Chin, A. Kiselyuk, B. Teply, G. Eng and R. Langer (2005). "Microfluidic system for studying nanoparticles and microparticles the interaction of with cells. Analytical Chemistry 77(17): 5453-5459.

Gopinath, S. C., T. S. Misono, K. Kawasaki, T. Mizuno, M. Imai, T. Odagiri and P. K. Kumar (2006). "An RNA aptamer that distinguishes between closely related human influenza viruses and inhibits haemagglutinin-mediated membrane fusion. J Gen Virol 87(Pt 3): 479-87.

Grama, C. N., D. D. Ankola and M. N. V. R. Kumar (2011). "Poly(lactide-co-glycolide) nanoparticles for peroral delivery of bioactives. Current Opinion in Colloid \& Interface Science 16(3): 238-245.

Green, L. S., D. Jellinek, R. Jenison, A. Ostman, C. H. Heldin and N. Janjic (1996). "Inhibitory DNA ligands to platelet-derived growth factor B-chain. Biochemistry 35(45): 1441324.

Guo, K.-T., G. Ziemer, A. Paul and H. Wendel (2008). "CELL-SELEX: Novel Perspectives of Aptamer-Based Therapeutics. International Journal of Molecular Sciences 9(4): 668678.

Guo, K. T., R. SchAfer, A. Paul, A. Gerber, G. Ziemer and H. P. Wendel (2006). "A new technique for the isolation and surface immobilization of mesenchymal stem cells from whole bone marrow using high-specific DNA aptamers. Stem Cells 24(10): 2220-31.

Guo, K. T., D. Scharnweber, B. Schwenzer, G. Ziemer and H. P. Wendel (2007). "The effect of electrochemical functionalization of Ti-alloy surfaces by aptamer-based capture molecules on cell adhesion. Biomaterials 28(3): 468-74.

Hahn, M. A., A. K. Singh, P. Sharma, S. C. Brown and B. M. Moudgil (2011). "Nanoparticles as contrast agents for in-vivo bioimaging: current status and future perspectives. Analytical and Bioanalytical Chemistry 399(1): 3-27.

He, X. X., L. Hai, J. Su, K. M. Wang and X. Wu (2011). "One-pot synthesis of sustainedreleased doxorubicin silica nanoparticles for aptamer targeted delivery to tumor cells. Nanoscale 3(7): 2936-2942.

Hicke, B. J., C. Marion, Y. F. Chang, T. Gould, C. K. Lynott, D. Parma, P. G. Schmidt and S. Warren (2001). "Tenascin-C aptamers are generated using tumor cells and purified protein. J Biol Chem 276(52): 48644-54.

Hoffmann, J., A. Paul, M. Harwardt, J. Groll, T. Reeswinkel, D. Klee, M. Moeller, H. Fischer, T. Walker, T. Greiner, G. Ziemer and H. P. Wendel (2008). "Immobilized DNA aptamers used as potent attractors for porcine endothelial precursor cells. J Biomed Mater Res A 84(3): 614-21.

$\mathrm{Hu}$, X. and X. Gao (2011). "Multilayer coating of gold nanorods for combined stability and biocompatibility. Physical Chemistry Chemical Physics 13(21): 10028-10035.

Huang, Y.-F., H.-T. Chang and W. Tan (2008). "Cancer cell targeting using multiple aptamers conjugated on nanorods. Analytical Chemistry 80(3): 567-572.

Janas, T. (2011). "The Selection of Aptamers Specific for Membrane Molecular Targets. Cellular \& Molecular Biology Letters 16(1): 25-39. 
Karkkainen, R. M., M. R. Drasbek, I. McDowall, C. J. Smith, N. W. G. Young and G. A. Bonwick (2011). "Aptamers for safety and quality assurance in the food industry: detection of pathogens. International Journal of Food Science and Technology 46(3): 445-454.

Kim, M. Y. and S. Jeong (2011). "In Vitro Selection of RNA Aptamer and Specific Targeting of ErbB2 in Breast Cancer Cells. Oligonucleotides 21(3): 173-178.

Kolishetti, N., S. Dhar, P. M. Valencia, L. Q. Lin, R. Karnik, S. J. Lippard, R. Langer and O. C. Farokhzad (2010). "Engineering of self-assembled nanoparticle platform for precisely controlled combination drug therapy. Proceedings of the National Academy of Sciences of the United States of America 107(42): 17939-17944.

Langer, R. (2001). "Perspectives: Drug delivery - Drugs on target. Science 293(5527): 58-59.

Liss, M., B. Petersen, H. Wolf and E. Prohaska (2002). "An aptamer-based quartz crystal protein biosensor. Analytical Chemistry 74(17): 4488-4495.

Lorger, M., M. Engstler, M. Homann and H. U. Goringer (2003). "Targeting the variable surface of African trypanosomes with variant surface glycoprotein-specific, serumstable RNA aptamers. Eukaryot Cell 2(1): 84-94.

Lupold, S. E., B. J. Hicke, Y. Lin and D. S. Coffey (2002). "Identification and characterization of nuclease-stabilized RNA molecules that bind human prostate cancer cells via the prostate-specific membrane antigen. Cancer Research 62(14): 4029-4033.

Mallikaratchy, P., Z. Tang, S. Kwame, L. Meng, D. Shangguan and W. Tan (2007). "Aptamer directly evolved from live cells recognizes membrane bound immunoglobin heavy mu chain in Burkitt's lymphoma cells. Molecular \& Cellular Proteomics 6(12): 22302238.

Mann, A. P., R. C. Bhavane, A. Somasunderam, B. L. Montalvo-Ortiz, K. B. Ghaghada, D. Volk, R. Nieves-Alicea, K. S. Suh, M. Ferrari, A. Annapragada, D. G. Gorenstein and T. Tanaka (2011). Thioaptamer Conjugated Liposomes for Tumor Vasculature Targeting.

Mann, A. P., A. Somasunderam, R. Nieves-Alicea, X. Li, A. Hu, A. K. Sood, M. Ferrari, D. G. Gorenstein and T. Tanaka (2010). "Identification of Thioaptamer Ligand against ESelectin: Potential Application for Inflamed Vasculature Targeting. Plos One 5(9).

Mayer, G. (2009). Nucleic Acid and Peptide Aptamers, Humana Press.

Mittal, G., D. K. Sahana, V. Bhardwaj and M. N. V. R. Kumar (2007). "Estradiol loaded PLGA nanoparticles for oral administration: Effect of polymer molecular weight and copolymer composition on release behavior in vitro and in vivo. Journal of Controlled Release 119(1): 77-85.

Ozalp, V. C., F. Eyidogan and H. A. Oktem (2011). "Aptamer-Gated Nanoparticles for Smart Drug Delivery. Pharmaceuticals 4(8): 1137-1157.

Ozalp, V. C. and T. Schafer (2011). "Aptamer-Based Switchable Nanovalves for StimuliResponsive Drug Delivery. Chemistry - A European Journal: DOI: 10.1002/chem.201101403.

Ruckman, J., L. S. Green, J. Beeson, S. Waugh, W. L. Gillette, D. D. Henninger, L. ClaessonWelsh and N. Janjic (1998). "2 '-fluoropyrimidine RNA-based aptamers to the 165amino acid form of vascular endothelial growth factor (VEGF(165)) - Inhibition of receptor binding and VEGF-induced vascular permeability through interactions requiring the exon 7-encoded domain. Journal of Biological Chemistry 273(32): 20556-20567. 
Salomon, D. S., R. Brandt, F. Ciardiello and N. Normanno (1995). "Epidermal Growth Factor-Related Peptides and Their Receptors in Human Malignancies. Critical Reviews in Oncology/Hematology 19(3): 183-232.

Schaefer, R., J. Wiskirchen, K. Guo, B. Neumann, R. Kehlbach, J. Pintaske, V. Voth, T. Walker, A. M. Scheule, T. O. Greiner, U. Hermanutz-Klein, C. D. Claussen, H. Northoff, G. Ziemer and H. P. Wendel (2007). "Aptamer-based isolation and subsequent imaging of mesenchymal stem cells in ischemic myocard by magnetic resonance imaging. Rofo-Fortschritte Auf Dem Gebiet Der Rontgenstrahlen Und Der Bildgebenden Verfahren 179(10): 1009-1015.

Shangguan, D., Z. C. Cao, Y. Li and W. Tan (2007). "Aptamers evolved from cultured cancer cells reveal molecular differences of cancer cells in patient samples. Clinical Chemistry 53(6): 1153-1155.

Shangguan, D., Y. Li, Z. Tang, Z. C. Cao, H. W. Chen, P. Mallikaratchy, K. Sefah, C. J. Yang and W. Tan (2006). "Aptamers evolved from live cells as effective molecular probes for cancer study. Proceedings of the National Academy of Sciences of the United States of America 103(32): 11838-11843.

Shangguan, D., L. Meng, Z. C. Cao, Z. Xiao, X. Fang, Y. Li, D. Cardona, R. P. Witek, C. Liu and W. Tan (2008). "Identification of liver cancer-specific aptamers using whole live cells. Analytical Chemistry 80(3): 721-728.

Sobolewska, B. W., M. Avci-Adali, B. Neumann, T. O. Greiner, A. Stolz, D. Bail, T. Walker, A. Scheule, G. Ziemer and H. P. Wendel (2010). "A novel method for isolation of endothelial progenitor cells for cardiac stem cell therapy. Kardiochirurgia I Torakochirurgia Polska 7(1): 61-65.

Soontornworajit, B. and Y. Wang (2011). "Nucleic acid aptamers for clinical diagnosis: cell detection and molecular imaging. Analytical and Bioanalytical Chemistry 399(4): 1591-1599.

Szmitko, P. E., M. J. Kutryk, D. J. Stewart, M. H. Strauss and S. Verma (2006). "Endothelial progenitor cell-coated stents under scrutiny. Can J Cardiol 22(13): 1117-9.

Tsai, Y.-M., W.-C. Jan, C.-F. Chien, W.-C. Lee, L.-C. Lin and T.-H. Tsai (2011). "Optimised nano-formulation on the bioavailability of hydrophobic polyphenol, curcumin, in freely-moving rats. Food Chemistry 127(3): 918-925.

Wan, Y. A., Y. T. Kim, N. Li, S. K. Cho, R. Bachoo, A. D. Ellington and S. M. Iqbal (2010). "Surface-Immobilized Aptamers for Cancer Cell Isolation and Microscopic Cytology. Cancer Research 70(22): 9371-9380.

Wang, A. Z., V. Bagalkot, C. C. Vasilliou, F. Gu, F. Alexis, L. Zhang, M. Shaikh, K. Yuet, M. J. Cima, R. Langer, P. W. Kantoff, N. H. Bander, S. Jon and O. C. Farokhzad (2008). "Superparamagnetic iron oxide nanoparticle-aptamer bioconjugates for combined prostate cancer imaging and therapy. Chemmedchem 3(9): 1311-1315.

Wendel, H. P., M. Avci-Adali and G. Ziemer (2010). "Endothelial progenitor cell capture stents - hype or hope? International Journal of Cardiology 145(1): 115-117.

Zhang, J., X. Jia, X.-J. Lv, Y.-L. Deng and H.-Y. Xie (2010). "Fluorescent quantum dot-labeled aptamer bioprobes specifically targeting mouse liver cancer cells. Talanta 81(1-2): 505-509.

Zhou, J. H. and J. J. Rossi (2011). "Cell-Specific Aptamer-Mediated Targeted Drug Delivery. Oligonucleotides 21(1): 1-10. 
Zhu, C. L., C. H. Lu, X. Y. Song, H. H. Yang and X. R. Wang (2011). "Bioresponsive Controlled Release Using Mesoporous Silica Nanoparticles Capped with AptamerBased Molecular Gate. Journal of the American Chemical Society 133(5): 1278-1281. 


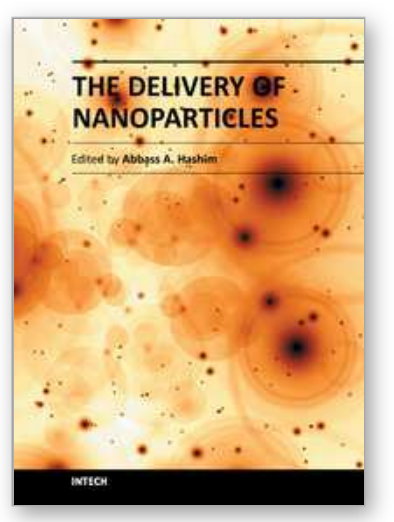

\author{
The Delivery of Nanoparticles \\ Edited by Dr. Abbass A. Hashim
}

ISBN 978-953-51-0615-9

Hard cover, 540 pages

Publisher InTech

Published online 16, May, 2012

Published in print edition May, 2012

Nanoparticle is a general challenge for today's technology and the near future observations of science. Nanoparticles cover mostly all types of sciences and manufacturing technologies. The properties of this particle are flying over today scientific barriers and have passed the limitations of conventional sciences. This is the reason why nanoparticles have been evaluated for the use in many fields. InTech publisher and the contributing authors of this book in nanoparticles are all overconfident to invite all scientists to read this new book. The book's potential was held until it was approached by the art of exploring the most advanced research in the field of nano-scale particles, preparation techniques and the way of reaching their destination. 25 reputable chapters were framed in this book and there were alienated into four altered sections; Toxic Nanoparticles, Drug Nanoparticles, Biological Activities and Nano-Technology.

\title{
How to reference
}

In order to correctly reference this scholarly work, feel free to copy and paste the following:

Veli C. Özalp and Thomas Schäfer (2012). Aptamer-Nanoparticle Bioconjugates for Drug Delivery, The Delivery of Nanoparticles, Dr. Abbass A. Hashim (Ed.), ISBN: 978-953-51-0615-9, InTech, Available from: http://www.intechopen.com/books/the-delivery-of-nanoparticles/aptamer-nanoparticle-bioconjugates-for-drugdelivery

\section{INTECH}

open science | open minds

\author{
InTech Europe \\ University Campus STeP Ri \\ Slavka Krautzeka 83/A \\ 51000 Rijeka, Croatia \\ Phone: +385 (51) 770447 \\ Fax: +385 (51) 686166 \\ www.intechopen.com
}

\author{
InTech China \\ Unit 405, Office Block, Hotel Equatorial Shanghai \\ No.65, Yan An Road (West), Shanghai, 200040, China \\ 中国上海市延安西路65号上海国际贵都大饭店办公楼 405 单元 \\ Phone: +86-21-62489820 \\ Fax: +86-21-62489821
}


(C) 2012 The Author(s). Licensee IntechOpen. This is an open access article distributed under the terms of the Creative Commons Attribution 3.0 License, which permits unrestricted use, distribution, and reproduction in any medium, provided the original work is properly cited. 